\title{
Corrigendum
}

\section{Corrigendum to "Implementation and Evaluation of WLAN 802.11ac for Residential Networks in NS-3"}

\author{
Andy Bubune Amewuda (D, Ferdinand Apietu Katsriku, and Jamal-Deen Abdulai \\ Department of Computer Science, University of Ghana, Accra, Ghana \\ Correspondence should be addressed to Andy Bubune Amewuda; abamewuda001@st.ug.edu.gh \\ Received 4 November 2018; Accepted 8 November 2018; Published 16 December 2018 \\ Copyright (c) 2018 Andy Bubune Amewuda et al. This is an open access article distributed under the Creative Commons \\ Attribution License, which permits unrestricted use, distribution, and reproduction in any medium, provided the original work is \\ properly cited.
}

In the article titled "Implementation and Evaluation of WLAN 802.11ac for Residential Networks in NS-3" [1], Reference [23] in the References list was incorrectly cited. The correct citation should be as follows.

[23] I. Selinis, "Performance study of 802.11n WLAN and MAC enhancements in ns-3," University of Piraeus, 2014, http://dione.lib.unipi.gr/xmlui/handle/unipi/7456.

\section{References}

[1] A. B. Amewuda, F. A. Katsriku, and J.-D. Abdulai, "Implementation and evaluation of WLAN 802.11ac for residential networks in NS-3," Journal of Computer Networks and Communications, vol. 2018, Article ID 3518352, 10 pages, 2018. 


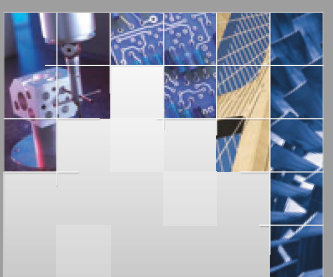

\section{Enfincering}
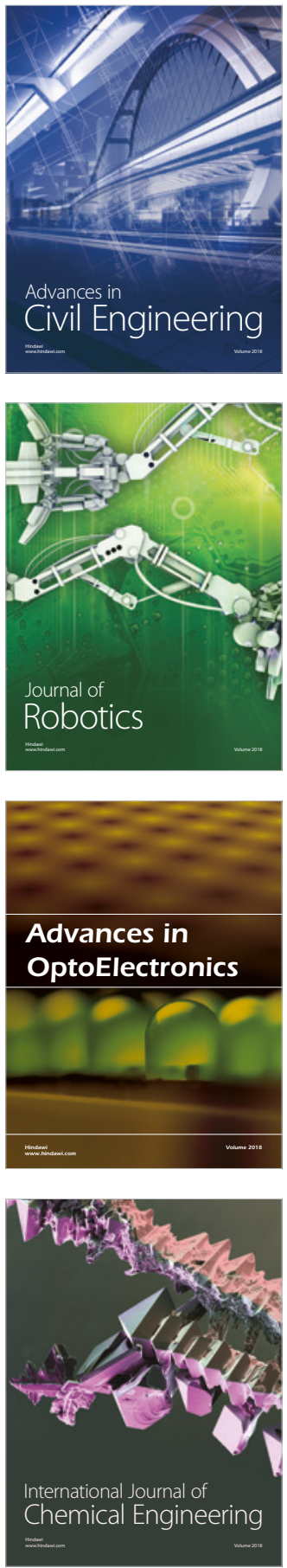

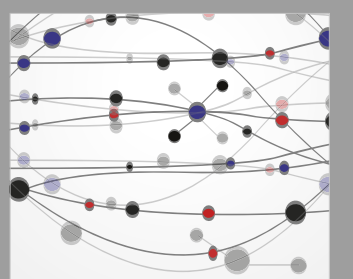

\section{Rotating \\ Machinery}

The Scientific World Journal

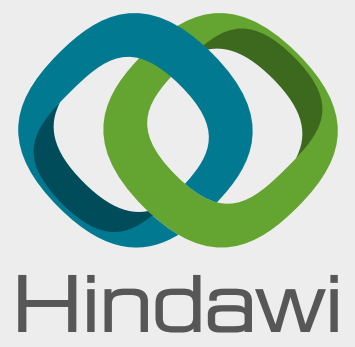

Submit your manuscripts at

www.hindawi.com
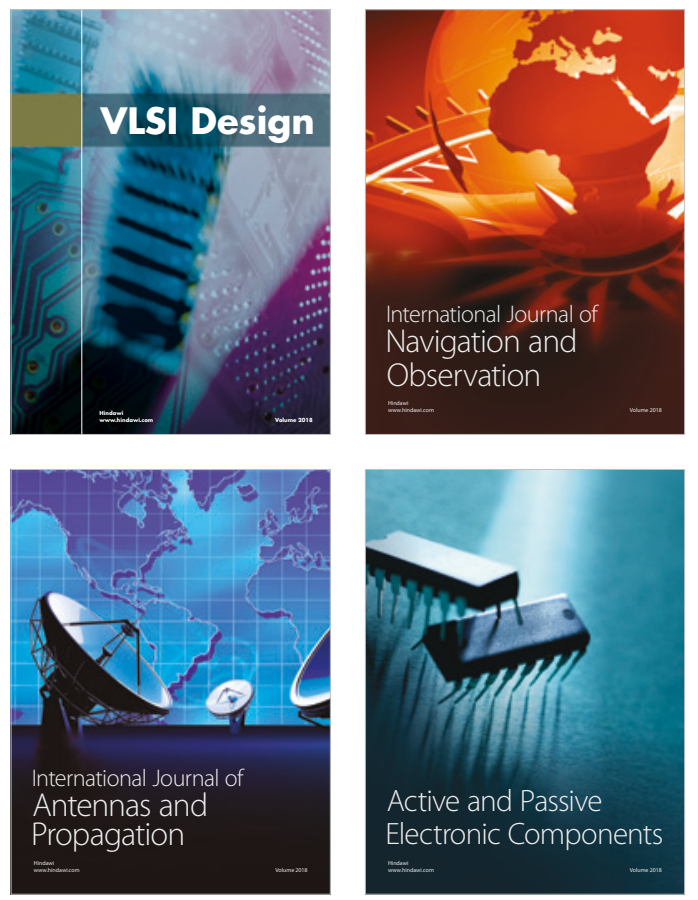
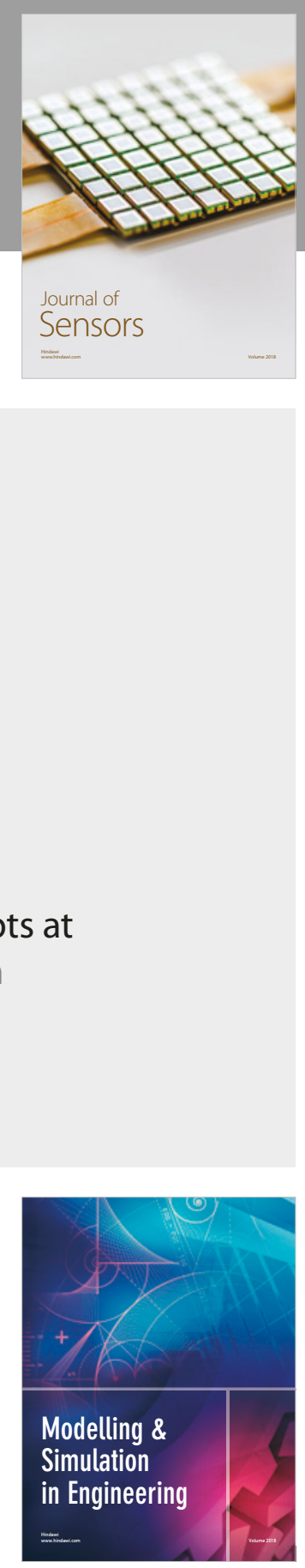

\section{Advances \\ Multimedia}
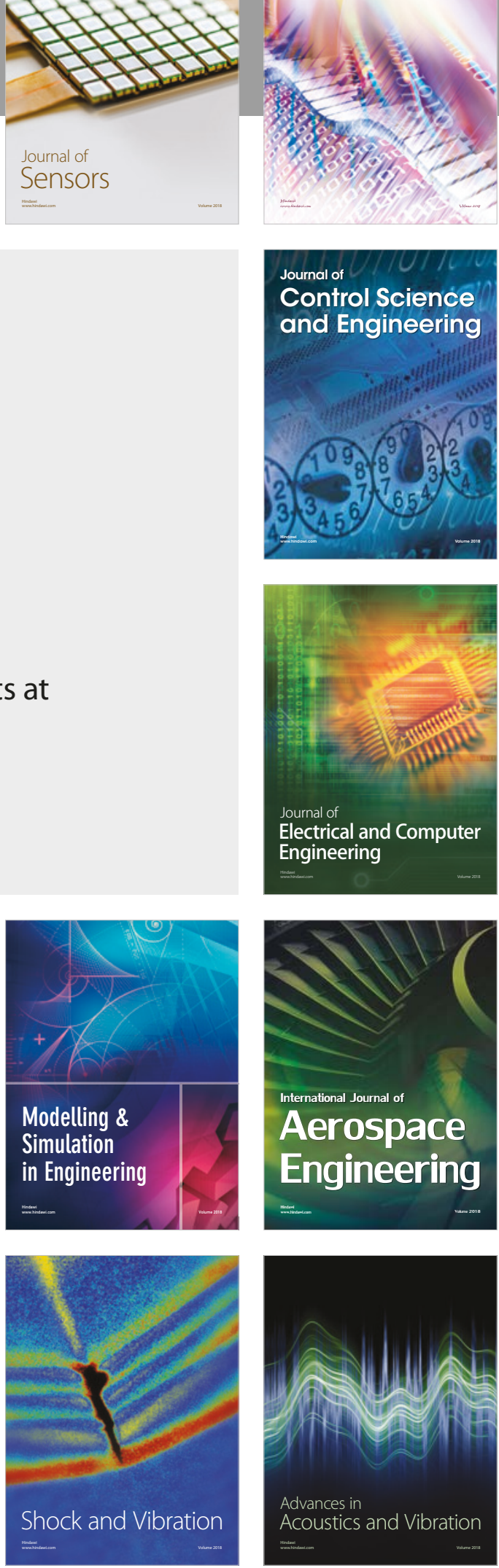